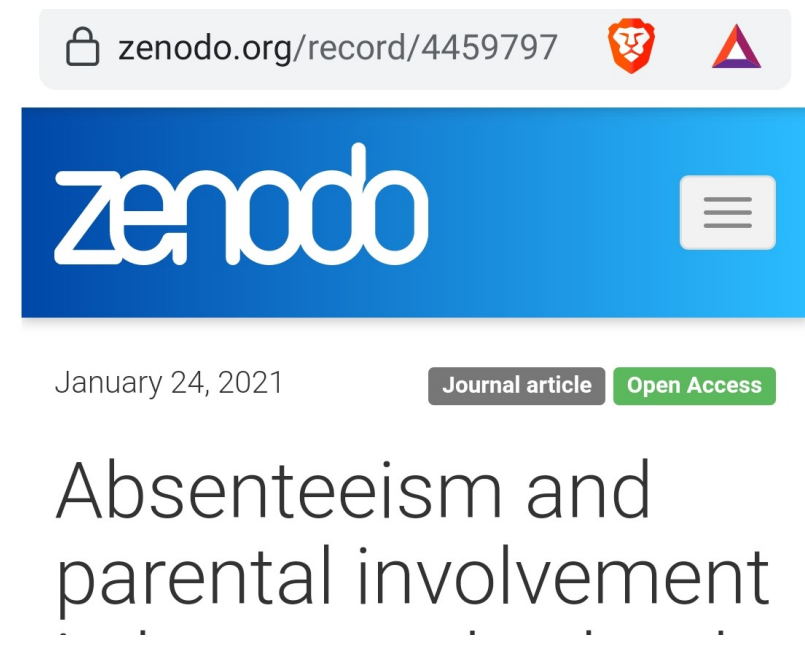

\title{
Absenteeism and parental involvement in home and school among middle school students of public school in northern Mindanao, Philippines: basis for intervention
}

\author{
Benzar Glen Grepon, Charry Mae Cepada
}

Funding: The author(s) received no specific funding for this work.

Potential competing interests: The author(s) declared that no potential competing interests exist.

\section{Abstract}

Educational attainment is an important determinant of one's success. Yet, absenteeism among adolescents jeopardizes chances of achieving their educational goals. Absenteeism can lead to an increasing disinterest in school and the chance of dropping out in school. Thus, this study determined how parental involvement affects absenteeism among 60 Middle school students of a public school. Specifically, it tested the extent of absenteeism of the respondents and the extent of parental involvement in school. Also, this study correlates students' absenteeism and parental involvement both at home and school. This study used descriptive-correlational method. A validated researcher-made questionnaire was used to determine the extent of absenteeism, extent of parental involvement and the respondents' perception towards parental involvement. Further, frequency, weighted mean, Pearson R correlation, and t-test for Two Independent Means were used as statistical tools in analyzing the gathered data. The study disclosed that parents were greatly involved at home but were moderately involved in school which contributed to the absenteeism of the students. Parental involvement in school was deemed important in terms of giving support and monitoring their children's attendance and 
performances in school. The findings revealed that parental involvement in school had a strong negative relationship with absenteeism. This meant that as parental involvement decreased, absenteeism among students increased. With $\alpha=0.05$, there was a significant relationship between parental involvement and absenteeism both at home and in school. Conversely, there was no significant difference on how the students and their parents perceived parental involvement. As gleaned in the data, both parents and students considered parental involvement as one of the important factors that enabled the students to pursue their studies. This study concludes that parental involvement in school and at home is correlated with absenteeism of the Middle school students in a public school. Parental involvement at home enables the parents to take good care of their children and show support in the learners' academic endeavors. Parental involvement in school also provides a big impression to the students. The presence of the parents in school boosts self-esteem and self-worth among their children.

\section{INTRODUCTION}

Educational attainment is an important determinant of one's success. Yet, absenteeism among adolescents jeopardizes chances of achieving their educational goals (Siziya, 2007). Too much student absenteeism can lead to an increasing disinterest in school. Schoenegerger (2011) states in his study that excessive absenteeism increases the chance of the students to drop out from school. The incidence of drop outs can lead to long term consequences such as lower average incomes, unemployment and higher rate of incarceration. It is also asserted that the students who drop out from school face a higher risk of poverty due to their inability to secure quality paying employment due to their lack of education and resources (Obrador, 2014).

Recent statistics from the Department of Education publicized that the overall student absence rate in the Philippines is $4.5 \%$. This means that one in ten school children are classified as "persistently absent". Accordingly, middle schools had a higher rate of persistent absence compared to primary schools. Moreover, unauthorized absence or absenteeism, whether persistent or not, also increased. Hence, surveyors asked children why they skip classes. The respondents enumerated anxiety, depression, bullying and having diminutive interest in the subjects taught in school among others led them to be absent from their classes.

Absenteeism is the tendency, chronic absence, practice or habit of being absent or to be away from school without a good reason. Thus, it has been viewed as an indicator of poor individual performance, as well as an indirect gap-building between students and teachers (Malcolm, 2003).

Absenteeism has become a major and continuous problem among high school students in many countries (Teasly, 2004). Indeed, several studies were conducted to answer why high school students miss classes. He also noted numerous risk factors that contribute to student 
absenteeism such as family, health, low income, poor school climate, drug and alcohol use, transportation problems, and community attitudes towards education. Furthermore, (Pehlivan , 2006) found that the major reason given by students for their non-attendance at school is that they were bored; they dislike the school and the lessons; they lacked encouragement from friends; and, they lack expectations about education.

Since absenteeism is one of the biggest problems faced in almost all of the public schools and that absenteeism could lead to students' drop-out, the Department of Education adheres to lessen the truancy among students by identifying the possible factors that contributes to absenteeism. Through DepEd Order, they have deepened the analysis of the students' excessive absenteeism from school. This enabled the department to point out some factors which include: teaching strategies, anxiety when at school, lack of interest, economic status, classroom environment, and lastly, the reason considered to be a critical factor is parents who do not value education or lack of parental involvement (Miguel, 2017). 